\title{
ALL THAT GLITTERS IS NOT GOLD: THE EFFECTS OF MATERIALISM, LUXURY PARTICIPATION, AND INCOME ON SUBJECTIVE WELL-BEING
}

\author{
Jeff Langenderfer, Meredith College, Raleigh, NC, U.S.A. \\ Bani Taunque, Meredith College, Raleigh, NC, U.S.A. \\ Richa Kulkarni, Meredith College, Raleigh, NC, U.S.A.
}

dx.doi.org/10.18374/JIFE-20-1.3

\begin{abstract}
For centuries, human beings have been told by philosophers, writers, and religious leaders that money cannot buy happiness, and indeed, current research strongly indicates that materialism, or a focus on material goods and consumption, reduces subjective well-being, a proxy for long-term happiness. Recent studies, however, have shown mixed results of the effects of consumption on well-being. Can buying things truly make people happier? This study, involving 400 Mechanical Turk participants, examines the interplay between Materialism, Income, Luxury Participation, and Subjective Well-Being (SWB). Consistent with prior research, results suggest that there is a negative main effect of Materialism on SWB. However, for higher income respondents, the effect is attenuated or absent. For those who have the means to participate in the market for luxuries, it seems that it isn't so bad to be materialistic.
\end{abstract}

Keywords: materialism, luxury, income, well-being 